LBL-35898

UC-404

\title{
DIRECT COLORIMETRIC DETECTION OF VIRUS BY A POLYMERIZED BILAYER ASSEMBLY
}

\author{
DEBORAH H. CHARYCH*, JON O. NAGY, WAYNE SPEVAK, \\ JOEL AGER, and MARK D. BEDNARSKI
}

\author{
Materials Sciences Division \\ Center for Advanced Materials \\ Lawrence Berkeley Laboratory \\ University of California \\ Berkeley, California 94720
}

January 1994

This work was supported by the Director, Office of Energy Research, Office of Basic Energy Sciences, Material Sciences Division, of the U.S. Department of Energy under Contract No. DE-AC03-76SF00098.

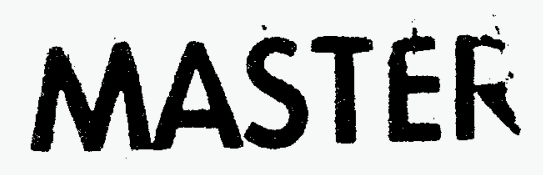




\section{DISCLAIMER}

This report was prepared as an account of work sponsored by an agency of the United States Government. Neither the United States Government nor any agency thereof, nor any of their employees, make any warranty, express or implied, or assumes any legal liability or responsibility for the accuracy, completeness, or usefulness of any information, apparatus, product, or process disclosed, or represents that its use would not infringe privately owned rights. Reference herein to any specific commercial product, process, or service by trade name, trademark, manufacturer, or otherwise does not necessarily constitute or imply its endorsement, recommendation, or favoring by the United States Government or any agency thereof. The views and opinions of authors expressed herein do not necessarily state or reflect those of the United States Government or any agency thereof. 


\section{DISCLAIMER}

Portions of this document may be illegible in electronic image products. Images are produced from the best available original document. 


\section{DIRECT COLORIMETRIC DETECTION OF VIRUS BY A POLYMERIZED BILAYER ASSEMBLY}

DEBORAH H. CHARYCH*, JON O. NAGY, Lawrence Berkeley Laboratory, Berkeley, CA; WAYNE SPEVAK, University of California, Berkeley, CA; JOEL AGER, MARK D. BEDNARSKI, Lawrence Berkeley Laboratory, Berkeley, CA.

\section{ABSTRACT}

Screening and detecting virus by receptor-ligand interactions presents an important challenge in medical and environmental diagnostics, and in drug development. We have developed a direct colorimetric detection method based on a polymeric bilayer assembly. The bilayer is composed of a self-assembled monolayer of octadecyl siloxane and a Langmuir-Blodgett layer of polydiacetylene. The polydiacetylene layer is functionalized with receptor-specific ligands such as analogs of sialic acid. The ligand serves as a molecular recognition element, while the conjugated polymer backbone signals binding at the surface by a chromatic transition. The color transition is readily visible to the naked eye as a blue to red color change and can be quantified by visible absorption spectroscopy. The color transition can be inhibited by the presence of soluble inhibitors. Raman spectroscopic analysis shows that the color transition may arise from binding induced strain on the material resulting in bond elongation and conjugation length reduction.

\section{INTRODUCTION}

Polydiacetylenes are attractive candidates for 'smart materials', primarily because of their unusual optical properties ${ }^{1,2}$. These materials are known to undergo dramatic chromatic transitions, typically from the 'blue phase' to the 'red phase', in response to a wide variety of environmental stimuli such as temperature ${ }^{3}$, mechanical stress $^{4}$, solvent ${ }^{5}$ and $\mathrm{pH}$ changes $^{6}$. These color shifts have been ascribed to changes in the molecular conformation of the side chains which in turn influence the electron density distribution of the conjugated polymer backbone.

We have developed a polymerized bilayer assembly based on functionalized polydiacetylene which responds colorimetrically to specific binding at the surface of the film (figure 1). The assembly is composed of a self-assembled monolayer of octadecylsilane (OTS) and a Langmuir-Blodgett (LB) monolayer of functionalized 
polydiacetylene. This film was designed to undergo a chromatic transition from blue to red solely due to receptor-ligand interactions occuring at the surface of the bilayer? .

Lipid monomers such as compound 1 (figure 2) are readily polymerized in monolayer films assembled at the air-water interface (Langmuir monolayers) 8 .. Therefore, the bilayer assembly incorporates both a molecular recognition site and a detection element. This simple color-based sensor enables rapid, qualitative detection of binding by visual inspection of the film or quantitative detection by visible absorption spectroscopy. Our initial investigations focused on the binding of the influenza virus to sialic acid. In addition to the medical and diagnostic significance of the influenza system, the interaction between the viral lectin and sialic acid is very well characterized. Lipid monomer 2, (figure 2) contains a carbon-linked sialic acid head group that provides a molecular recognition site for the viral lectin, hemagglutinin 9 . This report will describe the use of polydiacetylene bilayer assemblies functionalized with sialic acid for the colorimetric detection of influenza virus. The formation and characterization of the films, and a proposed model for the chromatic transition will be discussed.

\section{EXPERIMENTAL}

Mixtures of 2 to $5 \%$ of glycolipid monomer 2 and matrix lipid monomer 1 were spread on the water surface of a standard LB trough. The mixed monolayer was compressed and polymerized on the water surface using $254 \mathrm{~nm}$ UV radiation from a low pressure mercury lamp. The floating polymerized assembly was lifted by the horizontal touch method onto a glass slide previously coated with a selfassembled monolayer of OTS. The resulting bilayer assembly presents an array of carbohydrate ligands at the surface as in Figure 1. The tetraethylene glycol spacer in glycolipid 2 serves to extend the carbohydrate ligand beyond the carboxylic acid head groups of the matrix lipid 1.

Colorimetric assays were obtained by placing the blue into a sample cuvette containing phosphate-buffered saline $(\mathrm{pH} 7.4)$. The visible absorption spectrum was recorded. Influenza virus in PBS buffer ( $\mathrm{pH} 7.4$ ) was added to the cuvette by successive additions of 20 $\mu \mathrm{L}$ aliquots. The new absorption spectra were recorded after ca. 30 minutes of viral incubation. Alternatively, the spectra were recorded in pure buffer solution, and the sample removed and incubated with virus-containing solution in a separate chamber. The treated samples were rinsed with PBS buffer, and de-ionized water prior to their replacement in the cuvette. The new absorption spectra were 


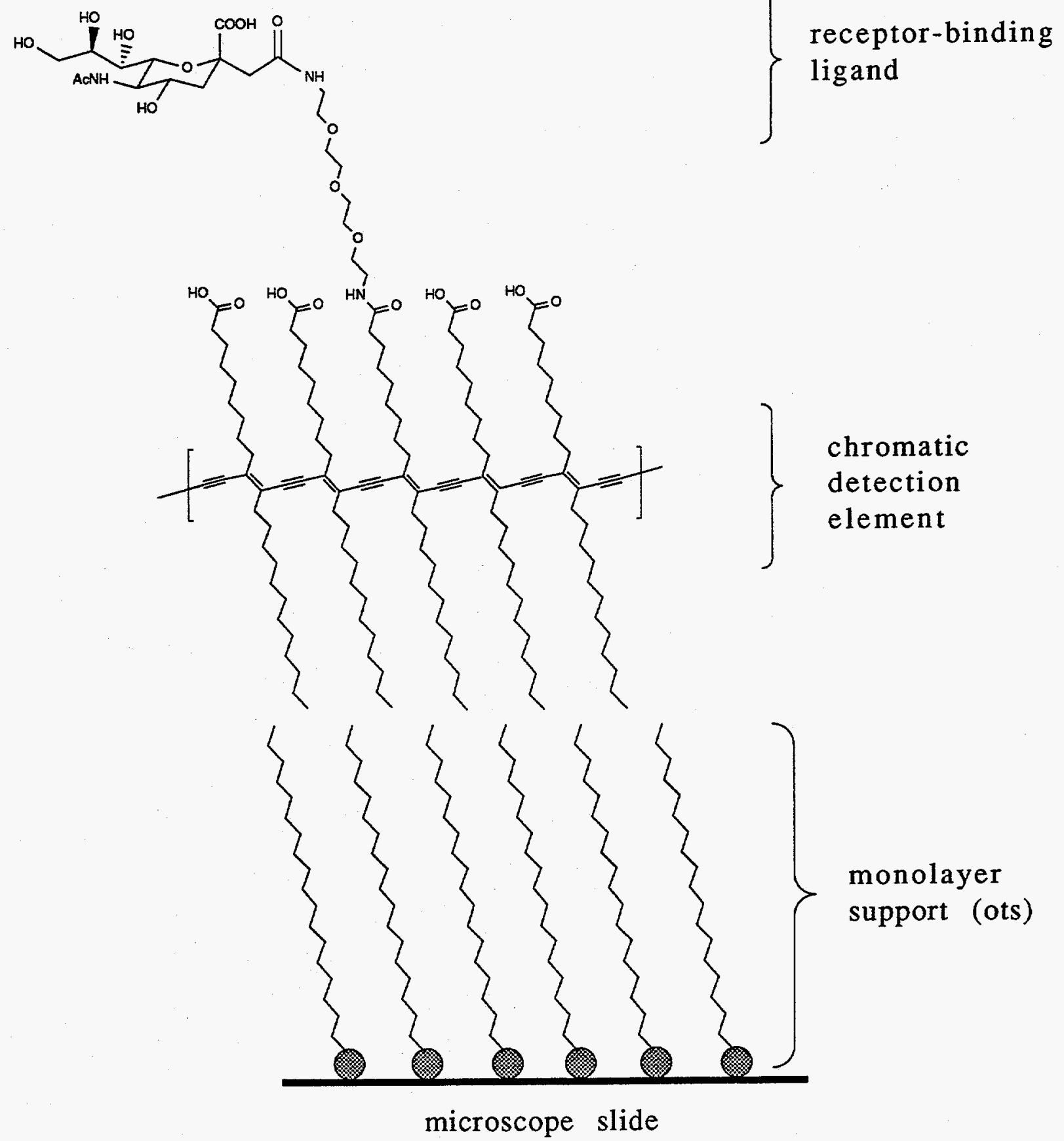

Figure 1. Schematic of the polymerized bilayer assembly. 

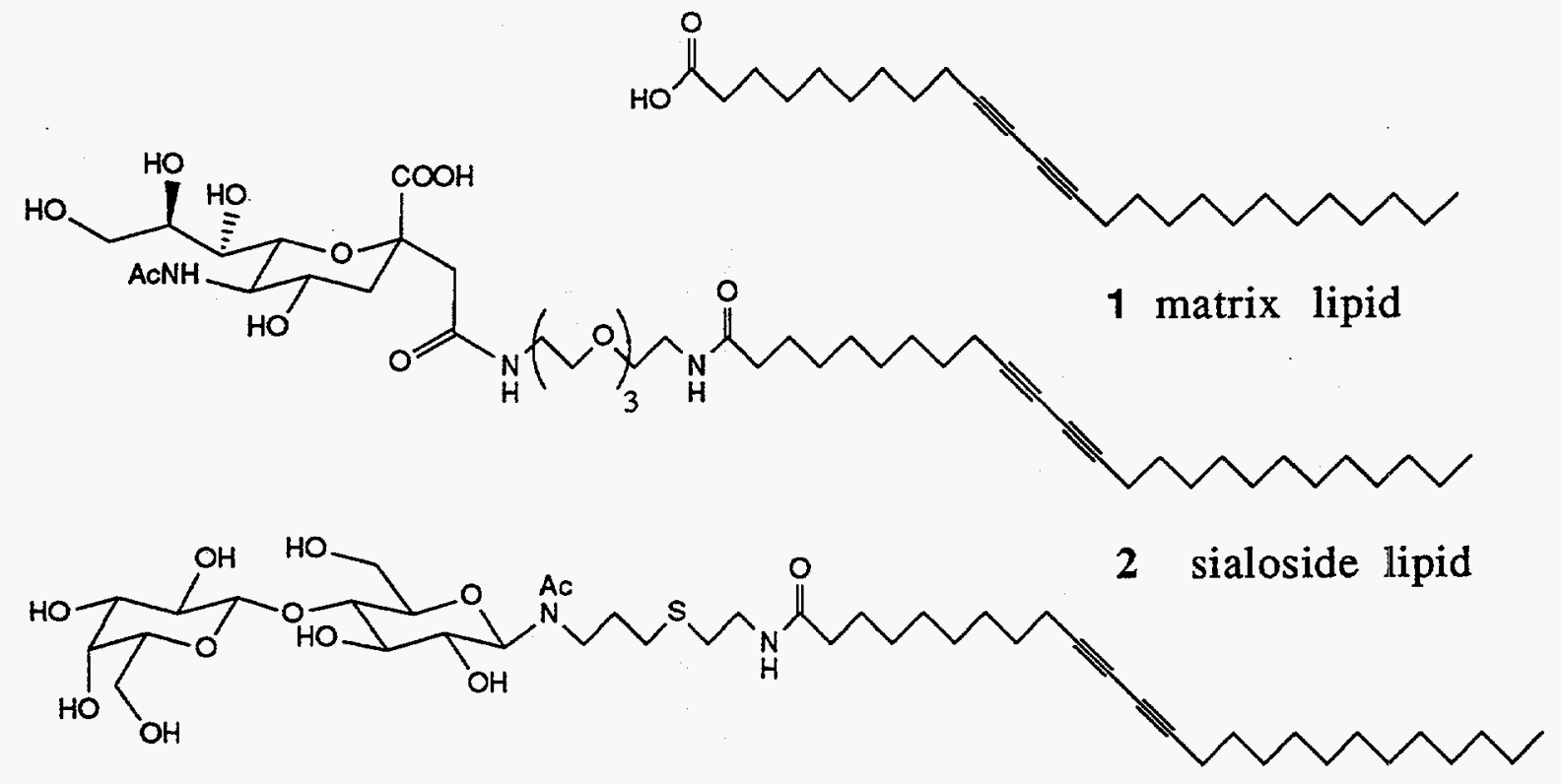

3 lactose lipid

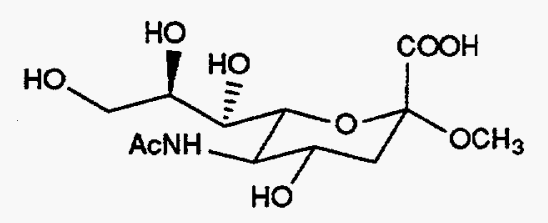

$\alpha$-methyl-N-acetyl neuraminic acid $(\alpha-\mathrm{O}-\mathrm{NeuAc})$

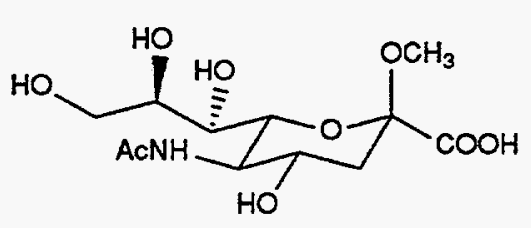

$\beta$-methyl-N-acetyl neuraminic acid $(\beta-\mathrm{O}-\mathrm{NeuAc})$

\section{4<smiles>OCCC1(O)OC(O)C(O)C(O)C1O</smiles>

$\alpha$-glucose

Figure 2. Compounds $1-3$ used in LB film formation and compounds 4 - 6 used in competitive inhibition experiments.

recorded in pure PBS buffer. Any observed changes in the spectra were permanent even in the absence of virus in the solution.

XPS depth profile analyses were obtained using a Phi 5300 spectrometer (Perkin-Elmer Instruments) using $\mathrm{MgK} \alpha$ radiation of $1253.6 \mathrm{eV}$. Survey spectra were recorded with a $45^{\circ}$ takeoff angle, $180 \mathrm{eV}$ pass energy, $400 \mathrm{~W}$ beam power. Rotation of the specimen holder allowed the takeoff angle to be varied from $15^{\circ}$ to $75^{\circ}$.

For Raman spectroscopy, the laser line employed as the Raman source was the $632.8 \mathrm{~nm}$ line from a He-Ne laser (Spectro-Physics) at $10 \mathrm{~mW}$ power. In some cases, a neutral density filter (ND 1.0) was 
used. Scattered light was detected with a microchannel plate photomultiplier (ITT).

\section{RESULTS AND DISCUSSION}

\section{Film characterization}

In order to verify that the headgroup functionalities of compounds $1-3$ are indeed localized at the surface of the film, and available for enzymatic cleavage, XPS depth profile analysis was used. The electron detected from the sample emerges from a vertical depth, $\mathrm{d}$, given by equation 1

$$
\mathrm{d}=3 \lambda \sin \alpha
$$

where $\lambda$ is the attenuation length of the emerging electron, and $\alpha$ is the electron escape angle (the angle between the electron analyzer and the surface plane) ${ }^{10}$. At $\alpha=90^{\circ}$ with respect to the surface plane, the signal arising from elements in the bulk of the film is maximized relative to elements localized at the surface. As $\alpha$ is decreased, the signal from elements at the surface becomes enhanced relative to that from the bulk. The location of an element can be deduced by measuring the intensity of its spectral peaks as a function of sample orientation, $\alpha$. The intensity variations can be related to those from other elements, producing an elemental depth profile. Thus, the angular variation of intensities for elements localized at the surface of the molecular film (If) and the intensities for elements at greater depth $\left(I_{d}\right)$ with respect to the surface is given by equations 2 and $3^{11}$

$$
\begin{aligned}
& \text { If } \propto\left(1-e^{-d / 1} \sin \alpha\right) \\
& I_{d \propto e^{-d} / 1 \sin \alpha}
\end{aligned}
$$

Elements localized at the surface show increasing intensties with decreasing electron escape angles while elements embedded in the bulk show decreasing intensities with decreasing electron escape angles. Figure 3 shows the relationship of the normalized intensities of $\mathrm{N}, \mathrm{F}, \mathrm{C}$, and $\mathrm{Si}$ to the electron escape angle for the polymerized bilayer assemblies. The intensities arising from the amide nitrogen, $\mathrm{N}_{1}$ s, carbonyl carbon $\mathrm{C}_{1 \mathrm{~s}}(\mathrm{carb})$, and fluorine, $\mathrm{F}_{1 \mathrm{~s}}$ atoms all increase 
with decreasing $\alpha$. In contrast, the intensity of the saturated carbon $\mathrm{C}_{1 \mathrm{~s}}$ (sat) remains fairly constant, and the intensity of the silicon $\mathrm{Si}_{2} \mathrm{p}$ declines steadily with decreasing electron escape angle. This data is consistent with the following elemental depth profile; the carbonyl carbons, amide nitrogens and fluorine atoms localized at the surface regions of the film, the saturated carbons at a greater relative depth with respect to the surface, and the silicon atoms at the greatest depth. This supports the representation of the bilayer assembly depicted in figure 1.

Further evidence for the location of the hydrophilic functionalites at the surface is obtained qualitatively from contact angle measurements. Prior to lifting the polydiacetylene monolayers, the OTS-treated glass slides have a water contact angle of $110^{\circ} \pm 0.5^{\circ}$. After lifting the polydiacetylene monolayers onto the OTS-treated glass slides, the wettability of the surface increases yielding a water contact angle of $47^{\circ} \pm 3^{\circ}$. This low contact angle indicates the presence of hydrophilic functionality at the surface, consistent with the horizontal touch method of film deposition.

Ellipsometric analysis of the polydiacetylene monolayer coated on HF-treated silicon indicates a film thickness of $\sim 40 \AA-$ in agreement with the expected value based on molecular modeling. This indicates that a monomolecular film is transferred from the water surface onto the solid support.

\section{Direct colorimetric detection}

The bilayer assembly has a visible absorption maximum of 620 $\mathrm{nm}$ and appears as a blue film. When the film is incubated with influenza virus (PBS buffer, $\mathrm{pH}$ 7.4), the binding of the viral hemagglutinin to the sialic acid residues on the surface results in a blue to red color transition which is visible to the naked eye. No color change is observed when the blue film is incubated with a blank solution of PBS buffer. This is the first example of a polydiacetylene color transition arising from affinity binding (affinitychromism) rather than thermal annealing (thermochromism). Previous studies have shown that LB films composed of lipid 1 undergo a blue to red color change when heated at $70^{\circ} \mathrm{C}$, which corresponds to the endothermal transition for lipid chain melting 12 . Lipid chain disorder and tangling decrease the effective conjugation length of the polydiacetylene 

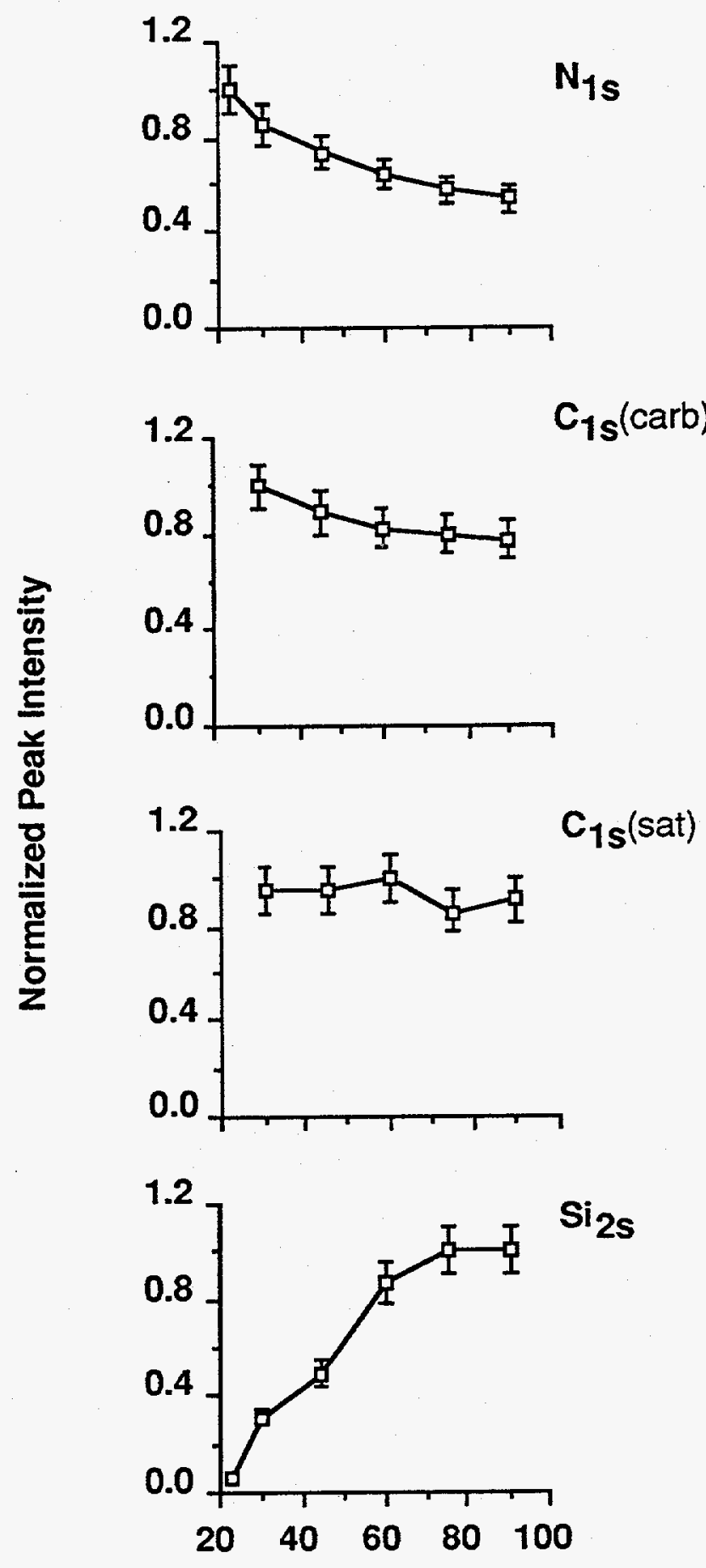

Take-Off Angle, a (degrees)

Figure 3. XPS depth profile analysis of a typical polymerized bilayer assembly. Intensities were normalized to the highest value observed. blue form. 


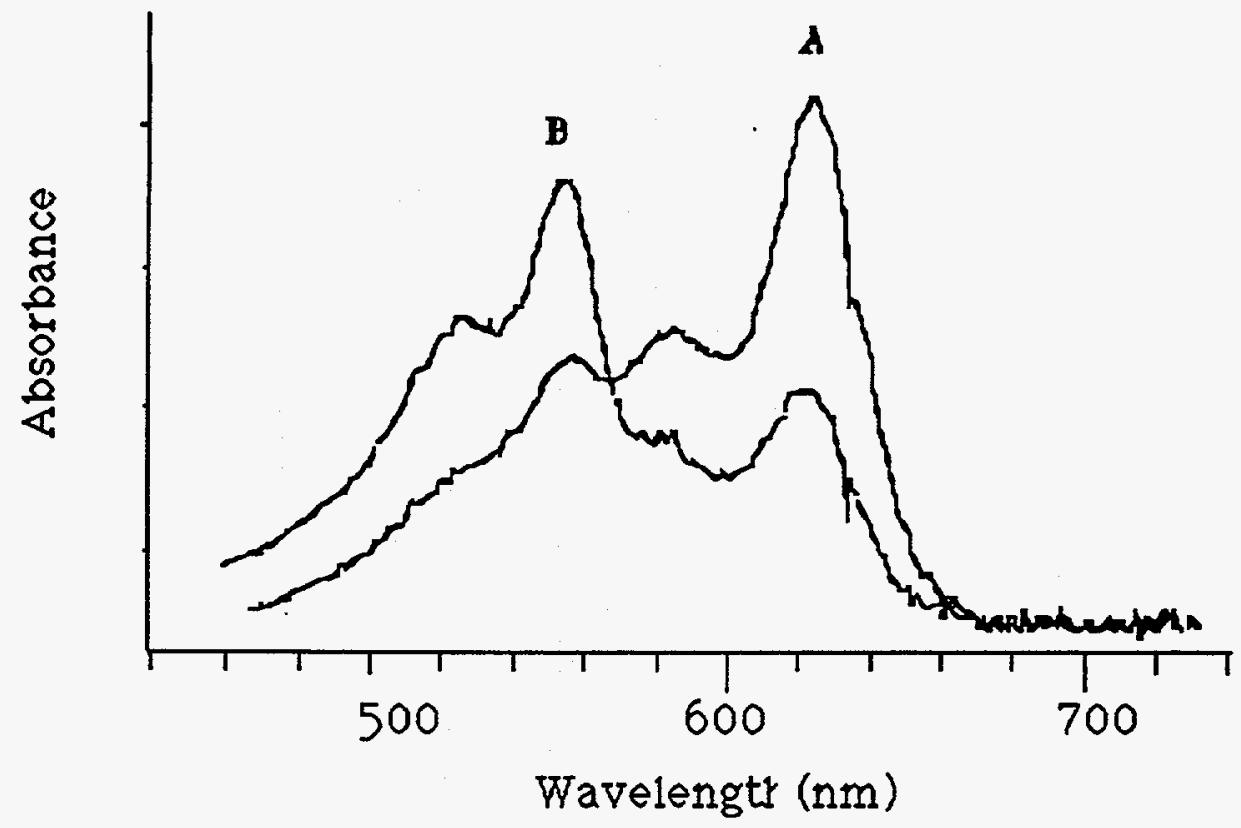

Figure 4. The visible absorption spectrum of a bilayer assembly containing glycolipid 2 before (A) and after (B) viral incubation. Spectra were recorded in PBS buffer.

backbone. Similarly, FTIR 12,13 , and X-ray data ${ }^{14,15}$ demonstrate that lipid chain packing of the red form of the polymer is different from that of the blue form. Thus, conformational changes in the lipid chains affect the optical properties of the polymer backbone. Binding of the viral hemagglutinin to the sialoside bilayer assembly appears to affect the lipid chain conformations, and hence, the electron distribution (conjugation length) of the polymer backbone. Further effects of viral binding on the polymer backbone are described later in the text.

In addition to qualitative evaluation by visual inspection, the degree of color change is readily quantified by standard visible absorption spectroscopy (Figure 4). The blue-colored film has a strong absorption maximum at $620 \mathrm{~nm}$ and a weaker absorption at $550 \mathrm{~nm}$. After incubation with influenza virus, a dramatic change in the visible absorption spectrum occurs. The maximum at $550 \mathrm{~nm}$ increases with a concurrent decrease in the maximum at $620 \mathrm{~nm}$, resulting in a red-colored film. The percent change in the relative intensity of the blue peak is defined as the colorimetric response (CR). The colorimetric response is directly proportional to the quantity of influenza virus (measured in hemagglutinating units, HAU, where one HAU is defined as the highest dilution of stock virus which completely agglutinates a standard erythrocyte suspension) ${ }^{16}$. Saturation of the colorimetric response occurs at ca. 80 HAU. 


\section{Competitive inhibition studies}

The specific nature of the interaction between the influenza virus and the sialoside film surface was confirmed by competitive inhibition assays, figure 5 . The known inhibitor of influenza hemagglutination, compound 4 , has a $\mathrm{K}_{\mathrm{d}}$ of $2 \mathrm{mM}$ as determined by a standard hemagglutination inhibition assay (HAI) ${ }^{16}$. Incubation of the sialoside bilayer assembly with influenza virus in the presence of the known binding inhibitor 4 results in no colorimetric response (CR $<0.5$ $\%)$ and the film remains blue. This demonstrates the inhibitor effectively competes with the sialoside surface for binding to the virus. When the blue film is exposed to the same quantity of influenza in the presence of a non-inhibitor (compound $5, \mathrm{~K}_{\mathrm{d}}>50 \mathrm{mM}$, or glucose, compound 6), the color change is identical to a film exposed to influenza alone.

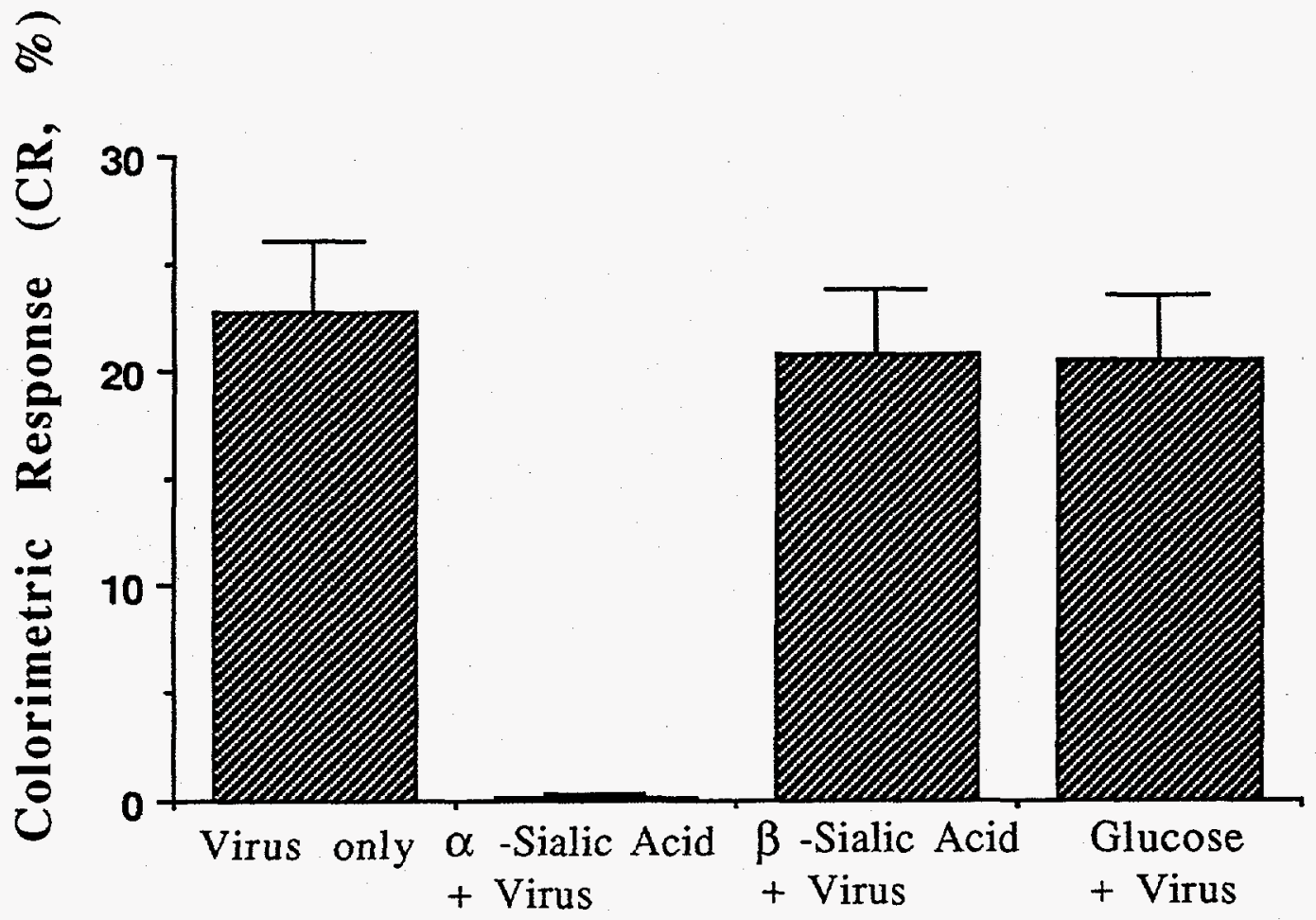

Figure 5. Inhibition of the colorimetric response by soluble ligands. Only compound 4 is an effective inhibitor. 
In order to test the capability of the film to predict the value of $\mathrm{K}_{\mathrm{d}}$ for an inhibitor, the colorimetric response was measured for a series of inhibitor concentrations. The colorimetric response increases in a linear fashion $\left(\mathrm{r}^{2}=0.995\right)$ with decreasing concentrations of inhibitor 4. Extrapolation of this plot to a colorimetric response of zero $(\mathrm{CR}=0 \%)$ gives the inhibitor concentration which completely prevents binding of the virus to the surface. This value represents the minimum inhibitor concentration required to effectively compete with the sialoside surface. The value obtained, $2.5 \pm 0.83 \mathrm{mM}$ per 4 HAU of virus is in agreement with the value of $2 \pm 1.1 \mathrm{mM}$ obtained by a standard HAI assay 16 and $2.8 \pm 0.30 \mathrm{mM}$ as obtained by NMR spectroscopy ${ }^{17}$. The inhibition assay described here is direct and easy to perform. This approach avoids the need for red blood cells which are used in the standard HAI assay. In addition, the subjectivity of reading microtiter plates in the standard HAI assay is replaced by a quantitative spectrophotometric method. This methodology could be applied to screening for new drug candidates or binding ligands.

\section{Effects of non-specific adhesion}

In order to asses the colorimetric response due to non-specific adhesion, two experiments were performed. In the first experiment, films incorporating lactose lipid 3 were incubated with influenza virus. Lactose is not a ligand for the hemagglutinin lectin. Incubation with $100 \mathrm{HAU}$ of virus, which is a concentration corresponding to a maximum response in the sialoside films, shows only a small colorimetric response $(\mathrm{CR}=1-2 \%)$. In the second experiment, films containing sialoside lipid 2 were exposed to concentrated solutions of bovine serum albumin. Again, the same small colorimetric response was observed. These results indicate that non-specific adsorption of virus or protein to the film surface does not produce the dramatic color change observed from specific receptor-ligand binding.

\section{Raman spectroscopic analysis}

Resonance Raman spectroscopy is an attractive technique to study the vibrations of the carbon atoms on the backbone of the 

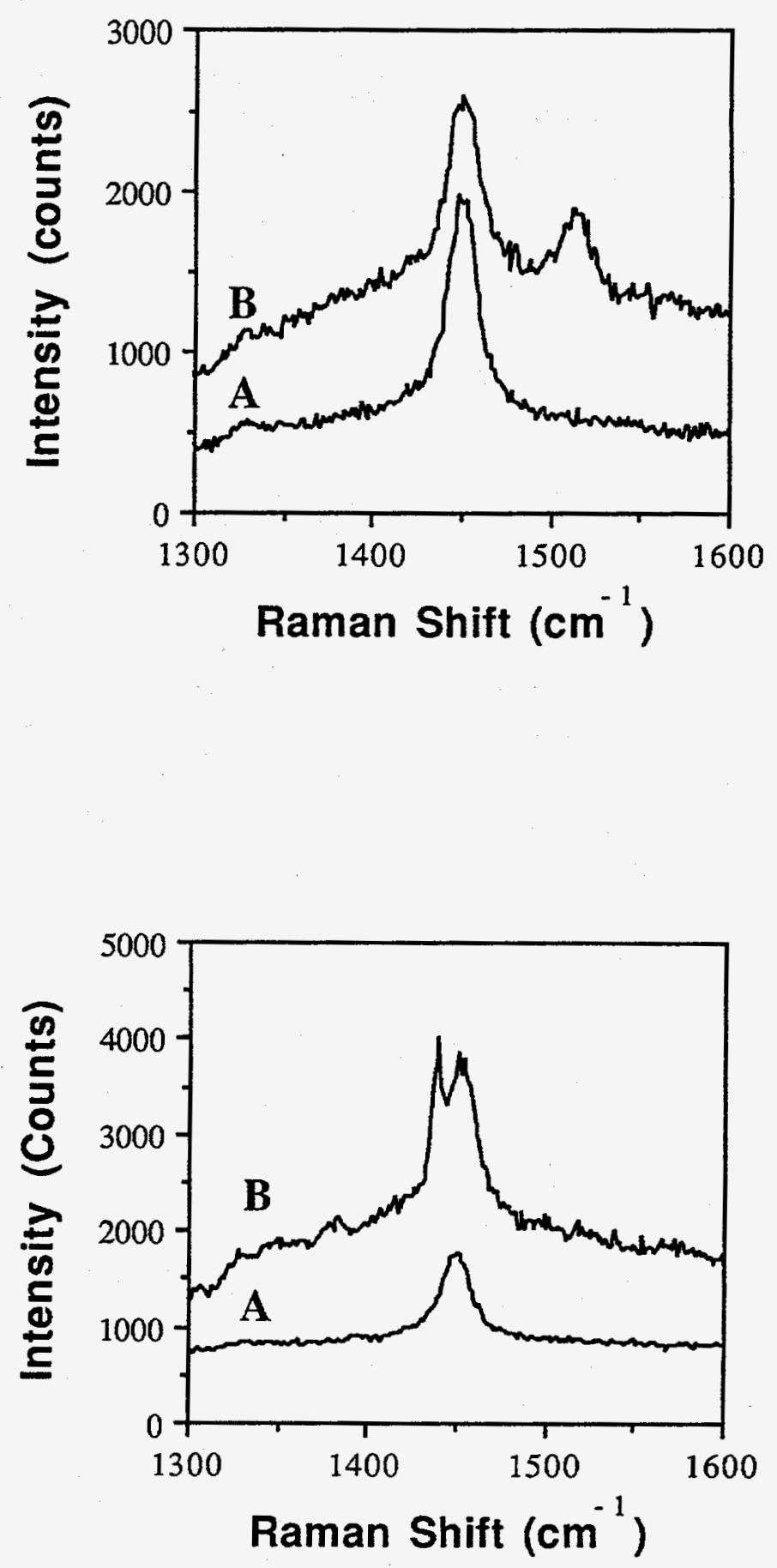

Figure 7. Raman spectra of double bond vibrations for films converted to the red form by thermal annealing (top) and viral binding binding (bottom). Spectra prior to treatment are labelled A, post-treatment spectra are labelled B. 
polydiacetylene chain. The vibrations of the double and triple bonds modulate the electronic states on the conjugated backbone which in this case, gives rise to the $620 \mathrm{~nm}$ absorption band. Thus, the vibrations of the double and triple bonds dominate the spectrum ${ }^{18}$.

In order to gain a better understanding of the changes which occur upon viral binding, a comparison was made between blue to red transitions arising from thermal annealing of the polymerized bilayer assembly, and blue to red transitions arising from binding of infuenza virus. Examination of the double bond stretching frequency at 1450 $\mathrm{cm}^{-1}$ (Figure 6,) indicates that thermal annealing of blue films at $85^{\circ} \mathrm{C}$ for 15 minutes produces a new peak at $1515 \mathrm{~cm}^{-1}$, characteristic of the red polymer ${ }^{13}$. This can be understood in terms of decreased delocalization, and increased double and triple bond force constants and stretching frequencies. The continued presence of the peak at $1450 \mathrm{~cm}^{-1}$ suggests that not all of the film has been perturbed.

Incubation of the films with influenza virus (ca. $100 \mathrm{HAU}$ ) produced the somewhat surprising shift of the double bond peak to lower frequencies, by ca. $10 \mathrm{~cm}^{-1}$. Similar shifts to lower frequency were observed for polydiacetylene fibers under an applied tensile stress ${ }^{19}$. In those studies the observed decrease in frequency could be explained by bond force constant anharmonicities. Stress-induced bond elongations result in decreased bond force constant (decreased spring stiffness) and lower vibrational frequencies. These results can be used to qualitatively model the binding-induced frequency shifts. Given that a single virus particle contains $>10^{2}$ receptors for sialic acid, it is conceivable that binding produces regions of film delamination in the vicinity of the virus particle. The delamination affects neighboring regions by local bond elongations. It is estimated that only $5-10 \%$ of the entire film surface is covered by virus, therefore the binding-induced strain has long-range effects, covering an area significantly greater than the area of a single virion (ca. $8 \mathrm{x}$ $10^{-11} \mathrm{~cm}^{2} /$ virus). This qualitative model will be tested further by a variety of techniques which probe the side chain conformations (FTIR and ${ }^{13} \mathrm{C}$ NMR spectrosocpy).

\section{CONCLUSIONS}

The bilayer assembly described here contains both the receptorbinding ligand and the capability to signal the specific binding event. Since ligands other than sialic acid could be incorporated into the film, affinitychromism offers the possibility of a general method for the direct detection of receptor-ligand interactions. This approach exploits the conserved binding specificity of bacterial and viral receptors and avoids the need for antibodies which bind protein 
epitopes subject to genetic shift and drift. The direct detection of binding events is an important discovery with wide-ranging applications in the areas of diagnostics and therapeutics. These films could be used for screening new drug candidates by inhibition of the colorimetric response. A combination of this methodology with a technique for preparing spatially resolved chemical libraries on the film surface would offer a powerful method for identifying new ligands.

\section{ACKNOWLEDGEMENT}

We thank M.E. Schaefer and J.H. Gilbert for virus protocols, technical help, and donation of influenza virus. Supported by the Director, Office of Energy Research, Office of Basic Energy Sciences, Division of Materials Sciences, and also the Division of Energy Biosciences of the U.S. Department of Energy (DE-AC03-76SF00098).

${ }^{1}$ For a review see: D. Bloor, R.R. Chance, in Polydiacetylenes, NATO ASI Series E. Applied Sciences, (Martinus Nijhoff Publishers, 1985).

2 H.J. Cantow in Advances in Polymer Science: Polydiacetylenes, 63, (Sspringer-Verlag, Berlin, 1984).

${ }^{3}$ R.R. Chance, G.N. Patel, J.D. Witt, J. Chem. Phys., 71, 206, (1979)

4R.A. Nallicheri, M.F. Rubner, Macromolecules, 24, 517, (1991).

5R.R. Chance, Macromolecules, 13, 396, (1980).

6N. Mino, H. Tamura, K. Ogawa, Langmuir, 8, 594, (1992).

${ }^{7}$ D.H. Charych, J.O. Nagy, W. Spevak, M.D. Bednarski, Science, 261, 585, (1993)

8D. Day, H. Ringsdorf, J. Polym. Sci., Polym. Lett. Ed., 16, 205, (1978).

${ }^{9}$ W. Spevak, J.O. Nagy, D.H. Charych, et al., J. Am. Chem. Soc., 115, 1146, (1993).

10D. Briggs, M.P. Seah, in Practical Surface Analysis, 2nd ed., (Wiley and Sons, Chichester, U.K., 1990). 
11 J.M. Slaughter, W. Weber, G. Guntherodt, C.M. Falco, Materials Research Society Bulletin, 39, (1992)

12 N. Mino, H. Tamura, K. Ogawa, Langmuir, 7, 2336, (1991).

13 M. Wenzel, G.H. Atkinson, J. Am. Chem. Soc., 111, 6123, (1989).

${ }^{14}$ G. Lieser, B. Tieke, G. Wegner, Thin Solid Films, 68, 77, (1980).

15 R.F. Fischetti, M. Filipkowski, A.F. Garity, J.K. Blaise, Phys. Rev. B., 37, 4714, (1988).

${ }^{16}$ T.J. Pritchett, R. Brossmer, U. Rose, J.C. Paulson, Virology, 160, 502, (1987).

${ }^{17}$ N.K. Sauter, et al., Biochemistry, 28, 8388, (1989).

18D.N.Batchelder, D. Bloor, in Advances in Infrared and Raman

Spectroscopy, volume 11, R.J.H. Clark, R.E. Hester, eds., (Wiley, Heyden, 1984).

19V.K. Mitra, W.M. Risen, Jr., R.H. Baughman, J. Chem. Phys., 66, 2731, (1977). 